\title{
Light and Heavy Heterosexual Activities of Young Canadian Adolescents: Normative Patterns and Differential Predictors
}

\author{
Trish Williams \\ Alberta Children's Hospital \\ Jennifer Connolly and Robert Cribbie \\ York University
}

The objectives of this research were to explore patterns of heterosexual activity in early adolescence and to examine the differential pathways to light and heavy heterosexuality. We utilized the National Longitudinal Survey of Canadian Children and Youth (NLSCY) in which heterosexual behaviors, as well as puberty, parenting processes, peer self-concept, and problem behaviors were examined. The heterosexual activities of the majority of 12- and 13-year-old adolescents were largely confined to light activities of hugging, holding hands, and kissing. Heavy activities such as petting and sexual intercourse were reported less often. Using predictor variables from Cycle 1 of the NLSCY when participants were 10- and 11-year-olds, SEM analyses indicated that puberty and higher peer selfconcept shared significant direct pathways to both light and heavy heterosexuality. Heavy sexual activity, however, was uniquely associated with the risk factors of adolescent problem behaviors. Positive and hostile parenting styles were indirectly associated with light sexual activity through peer selfconcept. Positive and hostile parenting styles were also indirectly associated with heavy sexual activity through both peer-oriented self-concept and problem behaviors. Results support differential patterns and predictors of light and heavy sexuality in early adolescence.

Requests for reprints should be sent to Trish Williams, Alberta Children's Hospital, Neuropsychology Service, 2888 Shaganappi Trail, NW, Calgary, Alberta, T3B 6A8, Canada. E-mail: tricia.williams@calgaryhealthregion.com 
For over 20 years, adolescent heterosexual activity has been the subject of intense psychological scrutiny (Jessor, Donovan, \& Costa, 1991; Jessor \& Jessor, 1977; Jessor, Van Den Bos, Vanderryn, Costa, \& Turbin, 1995). The most consistent finding to emerge is that sexual intercourse in early adolescence is associated with substantial psychosocial problems, as well as the increased risk of teenage pregnancy and sexually transmitted diseases (Alan Guttmacher Institute, 2001; Coley \& Chase-Lansdale, 1998; Resnick et al., 1997; Tubman, Windle, \& Windle, 1996). Because of these significant psychological and health risks, substantial efforts have been made to document the early risk factors associated with sexual intercourse (e.g., Capaldi, Crosby, \& Stoolmiller, 1996; Donenberg, Bryant, Emerson, Wilson, \& Pasch, 2003; French \& Dishion, 2003; Jacobson \& Crockett, 2000; Lynch, 2001; Zweig, Phillips, \& Duberstein-Lindberg, 2002). Much less attention has been directed to the patterns and predictors of lighter forms of heterosexuality, particularly in the early adolescent years (Halpern, Joyner, Udry, \& Suchindran, 2000; Kotchick, Shaffer, \& Forehand, 2001). Additionally, what is known of adolescent heterosexual activity stems predominantly from studies of American teenagers, despite evidence of variation in early adolescent sexuality between countries (Alan Guttmacher Institute, 2001). The present study makes use of a national survey of young Canadian adolescents to provide a picture of the range of heterosexual activities in early adolescence and to explore the distinction between light and heavy sexuality. Integrating problem behavior models of sexuality with developmental views of adolescent relationships, this study utilizes longitudinal information to differentiate between normative and atypical pathways to light and heavy heterosexuality.

In the last decade, a number of large-scale surveys of adolescent sexuality in the United States have been conducted to determine the age at which sexual intercourse is first initiated (e.g., Lammers, Ireland, Resnick, \& Blum, 2000; Magnusson, 2001; Resnick et al., 1997). Some reports suggest that, whereas there is a delay in age at first intercourse, the percentage of very young adolescents reporting that they have had sex has increased over time (AGI, 2001; Grunbaum et al., 2001, 2004; Resnick et al., 1997). According to retrospective data from the Youth Risk Behavior Surveillance Survey (YRBSS), $4 \%$ of White and 19\% of Black American adolescents initiated sexual intercourse by age 13, compared with $42 \%$ of White and $67 \%$ of Black American adolescents who initiated by the age of 17 (Grunbaum et al., 2001, 2004; Kann et al., 1998). Similar findings have also been shown by researchers in the American National Longitudinal Study on Adolescent Health (Add-Health) (Halpern et al., 2000; Resnick et al., 1997). 
In an effort to extend these prevalence rates beyond the American context, the Alan Gutmacher Institute (AGI, 2001) conducted secondary analyses of international data from adolescents in the age range of 15-19. These analyses revealed that American youth were consistently among the earliest in the initiation of sexual intercourse, whereas youth from Canada, France, and Britain reported the lowest levels of early adolescent intercourse (AGI, 2001). Although American studies demonstrate variation among sexual debut by ethnic background, these findings may not always be generalized to other countries. For example, in Canada, only small differences were detected, with White adolescents reporting earlier sexual debut than ethnic minorities (Maticka-Tyndale, McKay, \& Barrett, 2001). Overall, these national comparisons are suggestive of variation in early adolescent heterosexual activity and highlight the importance of examining patterns and predictors of adolescent sexuality internationally.

Problem behavior theory has strongly guided adolescent sexuality research (Jessor \& Jessor, 1977; Patterson, Reid, \& Dishion, 1992). In this framework, the concurrent roles of hostile family processes, peer involvement, and problem behaviors have been highlighted as key predictors of early adolescent sexual intercourse (Crockett, Bingham, Chopak, \& Vicary, 1996; Patterson et al., 1992; Tubman et al., 1996). Extending this perspective, Capaldi et al. (1996) proposed a more complex model in which early pubertal maturation is also considered to be a risk factor for precocious sexual behavior, along with negative family processes and problem behaviors occurring in the peer group. Studying high-risk males, these researchers found that early sexual intercourse could be predicted by the multiple influences of early pubertal maturation, family stress, association with deviant peers, and engaging in delinquent behaviors (Capaldi et al., 1996; Capaldi, Stoolmiller, Clark, \& Owen, 2002). These results, as well as those of French and Dishion (2003), also demonstrated that peer-based problem behaviors were the most proximal predictors of early intercourse and that parenting processes are only indirectly associated with early sexuality.

Despite the overwhelming focus of attention on the prediction of early sexual intercourse, this behavior represents only a small portion of sexuality among young adolescents (Halpern et al., 2000). Most young adolescents have not engaged in sexual intercourse, but at the same time do report engaging in other heterosexual behaviors (Halpern et al., 2000). These behaviors range from light sexual experiences such as holding hands, hugging, and kissing, to heavier behaviors such as petting over clothes or heavy petting under clothes (Smith \& Udry, 1985). Adolescent sexuality researchers have largely been interested in the overlap between reports of noncoital forms of sexuality and onset of sexual intercourse (Newcomer \& Udry, 1985; Rosenthal \& Smith, 1997; Smith \& Udry, 1985; 
Udry \& Billy, 1987). While the overlap between heavy sexuality and intercourse is confirmed among older adolescents, there is emerging evidence that many young adolescents engage in the cluster of light sexual behaviors and yet do not engage in heavier forms of sexuality. For example, over $85 \%$ of adolescents in the American Bio-Social Factors Survey reported light sexual activities including holding hands and kissing (Halpern et al., 2000). At the same time, heavy sexual behavior, such as petting, was reported by only $20 \%$ of these youth. Intercourse was the least common activity, reported by $6 \%$ of White females, 13\% White males and 35\% of Black females (this survey did not include Black males). These differential rates of light and heavy sexuality suggest that during early adolescence the progression of heterosexual behaviors may be sufficiently prolonged so that there is a phase when young people engage in light sexual activities without also engaging in heavier behaviors.

Recent research on the development of early adolescent dating provides a useful parallel to understand the distinction between light and heavy heterosexual activity (Connolly, Craig, Goldberg, \& Pepler, 2004). When the full range of romantic experiences is considered, a majority of younger adolescents report only light dating activities such as mixedgender affiliations, attending dances, and organized outings. Fewer of them report heavy dating activities, such as going out alone with a boy or girl, or going out on dates at night. Building from this research, we explore the possibility that there is a cluster of light heterosexual activities in early adolescence in which many young people hug, kiss, and hold hands, but do not engage in any behaviors involving genital contact.

Whether light heterosexual behaviors share similar or different predictors to those of heavy sexuality is not known. Given the progressive sequencing of sexuality over the full course of adolescence, it is likely that some predictors of light and heavy sexuality are shared. Following problem behavior theory, the range of possible predictors includes pubertal maturation, family processes, peer involvement, and problem behaviors (Capaldi et al., 1996, 2002). However, light and heavy sexuality are not equally risky in early adolescence, and so the predictors of light sexuality are most likely to include pubertal, peer, and family processes, but not problem behaviors. To better understand these normative predictors, we turn to adolescent developmental research on pubertal, peer, and family processes to identify those that are characteristic of the early adolescent period (Steinberg, 2001).

Puberty has been strongly connected to the emergence of heterosexual behavior among adolescents (Capaldi et al., 1996; Cavanagh, 2004; French \& Dishion, 2003; Udry, 1990; Udry \& Billy, 1987). This association is thought to be due to physical transitions in appearance, as well as hormonal changes (Brooks-Gunn \& Furstenberg, 1989). Given this strong as- 
sociation, pubertal development undoubtedly constitutes a significant predictor of engaging in any form of sexual behavior (e.g., Phinney, Jensen, Olsen, \& Cundick, 1990; Udry, 1979). The extent of pubertal maturation, however, is likely to be important in differentiating between those adolescents engaging in light sexuality from those reporting heavy sexuality. Additionally, puberty has been connected to changing family processes during adolescence (Steinberg \& Morris, 2001). For example, familial conflict and hostility increase around the onset of puberty (Montemayer, 1983; Steinberg, 1990). Despite this negativity, emotional closeness between parents and adolescents is reported to remain unchanged (Holmbeck \& Hill, 1991; Montemayer, 1983). Thus, the impact of pubertal maturation on adolescent sexual behavior requires assessment of its potential indirect effects through parenting processes as well as direct links.

A hallmark of early adolescence is an increase in peer self-concept as youth place more importance on popularity and involvement within their peer groups. Having a lot of friends and sharing more time with peers provide opportunities for sexual activity to occur (Brown, 1999; Feldman, Rosenthal, Brown, \& Canning, 1995). Consistent with these findings, perceiving oneself as popular and having a stronger peer self-concept have been associated with reports of heavier sexual behaviors and intercourse (Newcomer, Udry, \& Cameron, 1983). Whether a heightened peer-oriented self-concept during early adolescence might be associated with light sexuality is not known. Because the established link between peer-related problem behaviors and early sexuality is based on measures that do not distinguish between peer self-concept and problem behavior, it is not possible to determine their independent contributions. Yet a heightened peer self-concept in early adolescence does not necessitate the cooccurrence of an escalation of problem behaviors (Larson \& Richards, 1991; Pettit, Bates, Dodge, \& Meece, 1999). In this study, we separate our assessment of peer self-concept and problem behaviors and expect that a strong personal peer self-concept will be associated with both light and heavy sexuality, whereas problem behaviors will be associated only with heavy sexual activities.

Parenting practices clearly influence adolescent sexual behavior, but the relationship has been found to be indirect (Capaldi \& Patterson, 1994; Larzelere \& Patterson, 1990; Laub \& Sampson, 1988). For example, there is solid evidence that hostile parenting is indirectly linked with early onset of intercourse, through its associations with problem behaviors (Donovan \& Jessor, 1985; Elliott \& Morse, 1989). Other indirect links, however, may also be present. Currently, there is a lack of information on whether positive parenting can also have an influence on sexual behavior. Such an influence, however, may be inferred from studies linking positive parenting experiences to adolescent characteristics associated with sexuality. In this 
regard, adolescent peer self-concept is again highlighted (Coplan, Findlay, \& Nelson, 2004; Ladd \& Pettit, 2002). For example, nurturing parental relationships are linked to their adolescents' peer popularity and are known to foster an adolescent's ability to successfully join peer interactions, which then increases opportunities for sexual activity (Brown, Mounts, Lamborn, \& Steinberg, 1993; Hartup, 1979). It would follow that hostile parenting may be associated with youth's peer rejection and lower peer self-concept, which may be related to decreased opportunities for sexual behavior to occur. Putting these findings together, we propose in this study that parenting practices, both hostile and positive, indirectly influence adolescent sexuality through their associations with adolescent problem behaviors and a strong peer-oriented self-concept.

Integrating developmental patterns of puberty, peer self-concept, and family processes into adolescent problem behavior theory, we propose that there are both shared and discrete predictors of light and heavy heterosexuality. Specifically, as outlined in Figure 1, we expect that light heterosexuality will be directly associated with pubertal maturation and heightened peer-oriented self-concept, without concurrent problem behaviors. We also expect that light heterosexuality will be indirectly linked to positive parenting, mediated by peer-oriented self-concept and puberty.
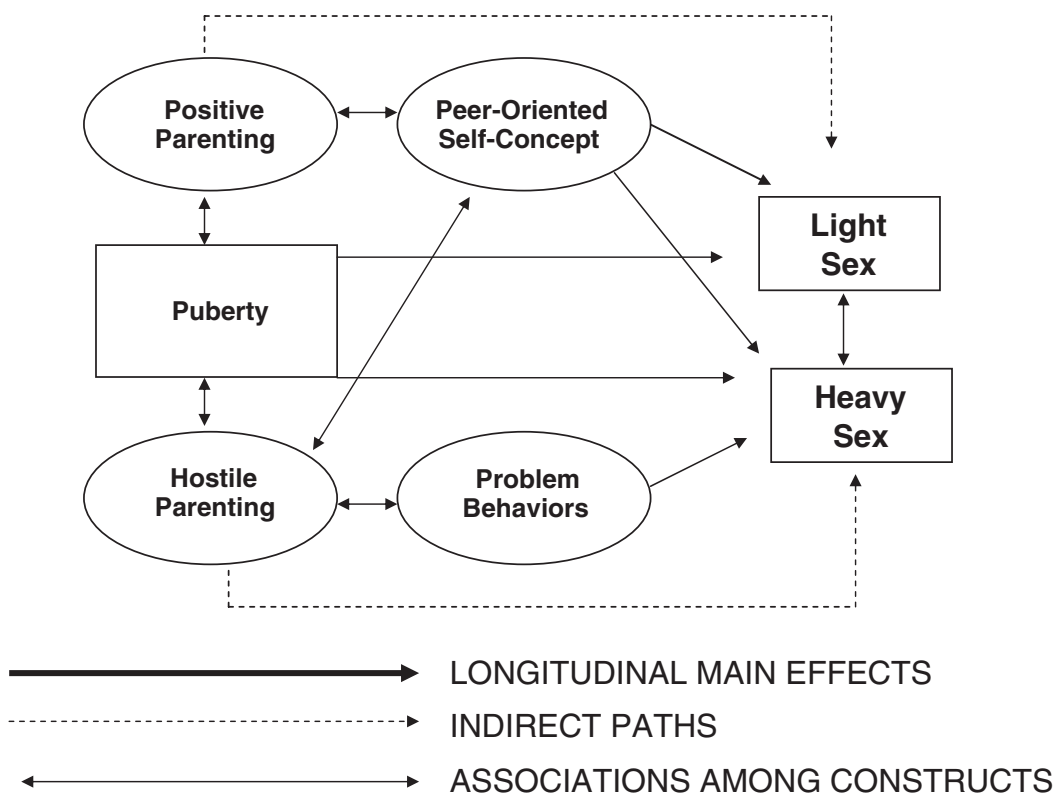

FIGURE 1 Hypothesized model predicting adolescent light and heavy heterosexuality. 
In contrast, as also shown in Figure 1, we expect heavy heterosexuality will be directly associated with increased problem behaviors in addition to earlier pubertal maturation and higher perceived peer self-concept. We also expect that heavy sexuality will be indirectly associated with hostile parenting through problem behaviors, peer-oriented self-concept, and pubertal maturation. Note that our model reflects the known connection between light and heavy forms of heterosexuality. The purpose of the current study, however, was to distinguish common and differential predictors of these two forms of sexual activity and thus does not assess their overlap.

To summarize, the current study utilized data from the Canadian National Longitudinal Survey of Children and Youth (NLSCY) to explore three objectives. First, we examined the frequency of light and heavy heterosexual behaviors in the cohort of early adolescent boys and girls when they were between 12 and 13 years of age. Second, we considered the possibility that there are a substantial number of young adolescents who report only light heterosexual behaviors and a smaller group who report heavy sexual behaviors as well as concurrent light sexuality. Finally, pubertal maturation, parenting processes, peer self-concept, and problem behaviors, identified when participants were 10 and 11 years of age, were explored to identify shared and differential links with light and heavy heterosexuality across a 2-year period.

\section{METHOD}

The NLSCY is a comprehensive survey of children's physical and psychological development that measures a wide range of demographic, physical, social, and individual factors. It is directed and managed by Human Resources Development Canada, under the auspices of Statistics Canada. Initiated in 1994, the survey employed a cohort sequential design with assessments conducted on a biannual basis. For the present study, we used data collected in Cycle 2 for the cohort of adolescents who were 12 and 13 years of age. This Cycle of data collection is important because the research protocol used at this time included the most extensive assessment of light and heavy heterosexual activities. We also utilized the puberty, peer, problem behavior, and family data collected in Cycle 1 when these adolescents were 10 and 11 years of age.

\section{Participants}

There were 1,959 (1,000 boys and 959 girls) Canadian adolescents who completed surveys in both Cycles 1 and 2 of the NLSCY. At Cycle 1 
(November 1994 to June 1995), the participants were 10 or 11 years of age (49\%-10 years; $51 \%$ - 11 years). At Cycle 2 (November 1996 to June 1997) the participants were 12 and 13 years old (50\% - 12 years; $50 \%-13$ years). The NLSCY recruited families to participate using a probabilityarea random sampling technique. In Cycle 1, a response rate of $86 \%$ of the probability sample was obtained. In Cycle 2, only respondents to Cycle 1 were followed and a 92\% retention rate was obtained (Michaud, 1999).

\section{Survey Procedure}

In-home interviews were conducted by Stats Canada interviewers. The session included interviews with the parents, as well as in-home questionnaires with parents and adolescents. A parent/guardian's signed consent was required in order to collect the information from the adolescents. To maximize privacy, participants were asked to fill out questionnaires in a separate room and return them to the interviewer in a sealed envelope. Participants were assigned sample identification numbers and assured that information would be kept confidential under the Statistics Act.

For the purposes of the larger study, Statistics Canada generated a sample of 20,025 Canadian infants, children, and adolescents aged 0-13 years, stratified by education, income, and geographic location. Ethnicity was not stratified and $91 \%$ of the sample was of European or Caucasian origin (i.e., White). Family composition was also not stratified and $72 \%$ of the adolescents were living in two-parent families (biological or adoptive). Although ethnicity and family composition were not stratified, our sample characteristics were quite similar to the national census statistics for ethnicity and family composition in 1996, which indicated that $11 \%$ of Canadians identified as an ethnic minority (i.e., non-White) and $73 \%$ of Canadian families were two-parent families (Statistics Canada, 1996). See Table 1 for a detailed outline of the current study's sample characteristics.

To approximate the national sample, sampling weights were applied to each record for all analyses. These weights are provided by the NLSCY and are tied to the weighting procedure utilized by the Canadian Labour Force Survey frame (Dufour, Gambino, Kennedy, Lindeyer, \& Singh, 1998).

\section{Measures}

Light and heavy heterosexual activities. To assess involvement in heterosexual activity, in the second cycle of data collection the adolescents were asked how often they had ever in their lifetime engaged in six sexual 
TABLE 1

Demographic Characteristics of the Sample

\begin{tabular}{lc}
\hline & Percentage of the Sample \\
\hline Gender & \\
Boys & 51 \\
Girls & 49 \\
Ethnocultural background & \\
European Canadian & 91 \\
Asian Canadian & 3 \\
Aboriginal Canadian & 5 \\
Caribbean-African Canadian & 1 \\
Other & 1 \\
Family structure & \\
Intact & 72 \\
Stepfamily & 8 \\
Single parent & 18 \\
Other & 2 \\
Household yearly income & \\
\$10-20,000 & 6 \\
\$20-30,000 & 10 \\
\$30-40,000 & 14 \\
\$40-50,000 & \\
\$50-60,000 & \\
\$60-80,000 & 16 \\
P80,000 & 14 \\
Nevince & 20 \\
Prince Edward Island & 20 \\
Nova Scotia & \\
New Brunswick & 23.0 \\
Quebec & 38.0 \\
Ontario & 4.0 \\
Manitoba & 4.0 \\
Saskatchewan & 10.0 \\
Alberta & 12.5 \\
British Columbia & .5 \\
Yukon and Northwest Territories & 5.0 \\
\hline
\end{tabular}

activities with someone of the opposite sex. These activities included: holding hands, hugging, kissing, petting above the waist, petting below the waist, and sexual intercourse. Possible responses included: $0=$ "Never," $1=$ "Once," $2=$ "A few times," and $3=$ "Often." 
Pubertal, peer, and family characteristics. Pubertal maturation, family processes, peer-oriented self-concept, and problem behaviors have been measured throughout the Cycles of NLSCY. However, aspects of the measurement instruments have changed somewhat from Cycle to Cycle. For example, the instruments used for the young adolescents in Cycles 1 and 2 are not identical. For this study, we therefore utilized the pubertal, peer, and family variables collected in Cycle 1, when the youth were 10 and 11 years of age.

Pubertal maturation. In the first year of data collection, participants were asked to rate their pubertal development, using items from the Pubertal Development Scale (Petersen, Crockett, Richards, \& Boxer, 1988). This is a well-established self-report measure of puberty with previously reported reliability and validity (e.g., Carskadon \& Acebo, 1993; Ellis \& Garber, 2000; Petersen et al., 1988; Rockett, Lynch, \& Buck, 2004). The objective of this scale is to determine adolescents' perceptions of their pubertal development in key physiological domains. These domains differ somewhat for each gender. For example, girls were asked "Have you begun to menstruate?" to which they could respond "Yes" or "No." Another question asked only of girls was: "Have your breasts begun to grow?" Questions asked of boys included: "Have you noticed a deepening of your voice?" and "Have you begun to grow hair on your face?" Both boys and girls were asked: "Would you say that your body hair ("body hair" means underarm and pubic hair) has begun to grow?" Responses to these questions included: "Not yet started," "Barely started," "Definitely underway," and "Seems completed" and were coded 0-3, respectively. To be consistent in scoring, responses to the menstruation question were coded 0 for "No" and 3 for "Yes." Standardized scores were created for each question separately, controlling for gender and age, and then summed to create a summary puberty score. The Cronbach $\alpha$ value for this score is .76.

Positive parenting. In Cycle 1, three indices of positive parenting were administered, one to the parent (Positive Interaction) and the others to the adolescent (Parental Nurturance and Parental Monitoring). The Positive Interaction Scale is based on five items from Strayhorn and Weidman's (1988) Parenting Practices Scale. Sample items include "How often do you 'praise him/her?"' and "How often do you laugh together?" The items were rated on a Likert scale ranging from 0 ("never") to 5 ("many times each day"). The total score ranged from 0 to 25 , a high score indicating positive interactions. The Cronbach $\alpha$ value was .81. The Parental Nurturance Scale used five items from Lempers, Clark-Lempers, and Simons (1989). Two sample items are "My parents (or stepparents) smile at me" and "My parents speak of the good things I do." Response options range 
from 0 ("never") to 3 ("very often"). The total score ranged from 0 to 15 , with a high score indicating a high degree of parental nurturance perceived by the child. The Cronbach $\alpha$ value was .77. The Parental Monitoring Scale was based on five items from Lempers et al. (1989). Two sample items are "My parents (stepparents) want to know exactly where I am and what I'm doing," and "My parents find out about my misbehavior." Response options range from 0 ("never") to 3 ("very often"). The total score ranged from 0 to 15 , a high score indicating a high degree of parental monitoring received by the child. The Cronbach $\alpha$ value was .54 .

Hostile parenting. At Cycle 1, three indices of hostile parenting were administered, two to the parent (Hostile-Ineffective Parenting and Punitive Interactions) and one to the adolescents (Inconsistent Parenting). Both the Hostile-Ineffective Parenting and Punitive Interactions Scales were adapted from Strayhorn and Weidman's (1988) Parenting Practices Scale. Hostile-Ineffective Parenting included seven items, such as, "How often do you get annoyed with your child for saying or doing something he/she is not supposed to?" and "How often do you get angry when you punish your child?" Punitive Interactions included four items, with "When your child breaks the rules or does something he/she is not supposed to, how often do you 'Raise your voice, scold or yell at him/her?', and 'Use physical punishment?"' Response categories to items on the Hostile-Ineffective and Punitive scales ranged from 1 ("never") to 5 ("many times each day/ all the time"). Total scale scores for the Hostile-Ineffective scale varied between 7 and 35, a high score indicating increased hostile interactions. Total scale scores for the Punitive Interactions varied between 4 and 20, a high score indicating increased punitive interactions. The Cronbach $\alpha$ values for the Hostile Parenting and Punitive Parenting scales were .71 and .57, respectively. To assess Inconsistent Parenting, six items were adapted from Lempers et al. (1989). Sample items include "My parents (or stepparents) 'soon forget a rule they have made,' and 'threaten punishment more often then they use it."' Response options range from 0 ("never") to 3 ("very often"). The total score ranged from 0 to 18 , high scores indicating a high degree of inconsistent parenting perceived by the child. The Cronbach $\alpha$ value for this scale is .60 .

Peer self-concept. Peer self-concept was assessed using the Peer Relations subscale (four items) from the Marsh Self-Description Questionnaire (Marsh \& Gouvernet, 1989). Sample items included "I have a lot of friends" and "Most other kids like me," which are rated on a Likert scale ranging from 1 ("false") to 5 ("true"). The total score ranged from 4 to 20, with high scores indicating a high perception of peer popularity or high peer self-concept. The Cronbach $\alpha$ value for this scale is .80 . 
Problem behavior. In Cycle 1, three indices of problem behaviors were completed by the adolescent, including measures of Conduct Disorder and Physical Aggression, Problem-Deviant Behaviors, and Social Aggression. Conduct Disorder and Physical Aggression was assessed using six items from the Youth Self-Report (Achenbach \& Edelbrock, 1991). Sample items included "I get into many fights" and "I threaten people." The items were rated on a Likert scale ranging from 0 ("never or not true") to 2 ("often or very true"). The total score ranged from 0 to 12, and the Cronbach $\alpha$ value was .74. Problem-Deviant Behaviors were assessed with five items adapted from the National Longitudinal Survey of Youth (Mott \& Quinlan, 1993). Sample items included "In the past year how often did you 'stay out all night without permission?', 'get drunk?' and 'have you been questioned by the police about anything you might have done such as stealing, damaging property or anything else?"' These items were rated on a scale of $0-3(0=$ never, $1=$ once, $2=$ twice, $3=$ more than twice $)$. The total score ranged from 0 to 15 , and the Cronbach $\alpha$ value was .77. Finally, Social Aggression was assessed using five items from Lagerspetz, Björkqvist, and Peltonen's (1988) scale. Sample items included "When I'm mad at someone, 'I try to get others to dislike him/her' and 'I say bad things behind the other's back."' These items were rated on a Likert scale ranging from 0 ("never or not true") to 2 ("often or very true"). The total score ranged from 0 to 10 , and the Cronbach $\alpha$ value was .73.

Family environment. The NLSCY provides assessments of family socioeconomic status and family composition, which we employed in our analyses as control variables.

Socio-economic status. In Cycle 1, socio-economic status of the participants was determined using five variables: years of schooling for principal main caregiver (PMK) and spouse, the Pineo-Porter (Pineo, Porter, \& McRoberts, 1977) occupation code for the PMK and spouse transformed to the logit distribution, and household income. This information was based on the PMK's responses to questions regarding his or her own education completed, occupation and income, as well as for their spouse, if applicable. Each variable was standardized to have a mean of 0 and a standard deviation of 1 . In the standardization of the spouse/partner variables, if the PMK did not have a spouse/partner, these records were ignored. The socio-economic composite was then calculated by taking the unweighted average of the five standardized variables.

Family composition. Family composition was also assessed at Cycle 1 and participants were coded as being in two-parent families (biological or adoptive parents) or one-parent families (single parents, step families, or other). 


\section{RESULTS}

\section{Patterns of Light and Heavy Heterosexual Behaviors Among 12 and 13 Years Old Canadian Adolescents}

We first examined the frequency ratings of each heterosexual behavior. Most adolescents reported scores of 0 ("never") or 1 ("once) and so each score was significantly skewed. Therefore, we chose to dichotomize the responses into scores of 0 ("never) and 1 ("ever"). The frequencies of participants reporting ever engaging in each of the six behaviors are shown in Table 2. Holding hands and hugging were reported by approximately $60 \%$ of the adolescents, and kissing was reported by approximately $52 \%$ of the sample. As expected, petting, either above or below the waist, was reported by fewer adolescents, approximately $25 \%$ of the sample. Sexual intercourse was reported very infrequently, by $<3 \%$ of girls and by $<5 \%$ of boys. As shown in Table $2, \chi^{2}$ tests indicated that 13-yearold adolescents reported engaging in all heterosexual behaviors more than did 12-year-olds and that more boys reported heavy behaviors than girls.

Light and heavy heterosexual activity. To evaluate whether some adolescents in the sample showed a distinct pattern of heterosexuality consisting of light sexual activities only, adolescents were assigned to one of three categories, based on their responses to the heterosexual activities items. Adolescents who reported never having engaged in any of the six sexual activities were classified into a no sex category. Adolescents who reported having engaged in at least one of the light sexual activities (hold

TABLE 2

Percentages of Canadian Adolescents Reporting Ever Engaging in Light and Heavy Heterosexual Activities

\begin{tabular}{|c|c|c|c|c|c|c|}
\hline & \multicolumn{2}{|c|}{12 Year Olds } & \multicolumn{2}{|c|}{13 Year Olds } & \multicolumn{2}{|c|}{$\chi^{2}(1,1,779)$} \\
\hline & Boys (\%) & Girls (\%) & Boys (\%) & Girls (\%) & Gender & Age \\
\hline Holding hands (\% ever) ${ }^{\mathrm{a}}$ & 49 & 49 & 60 & 58 & NS & $18.40^{* * *}$ \\
\hline Hugging $(\% \text { ever })^{\mathrm{a}}$ & 42 & 48 & 62 & 60 & NS & $45.49^{* * *}$ \\
\hline Kissing $(\% \text { ever })^{\mathrm{a}}$ & 36 & 38 & 54 & 51 & NS & $43.25^{* * *}$ \\
\hline Petting above waist (\% ever) $)^{a, b}$ & 20 & 16 & 33 & 26 & $7.55^{* * *}$ & $35.00^{* * *}$ \\
\hline Petting below waist $(\% \text { ever })^{a, b}$ & 15 & 9 & 26 & 18 & $15.94^{* * *}$ & $30.23^{* * *}$ \\
\hline Sexual intercourse (\% ever) $)^{a, b}$ & 2 & 2 & 7 & 3 & $7.43^{* *}$ & $15.43^{* * *}$ \\
\hline
\end{tabular}

\footnotetext{
${ }^{a}$ Significant difference across age.

${ }^{\mathrm{b}}$ Significant difference across gender.

$* * p<.01$
} 
hands, hug, and kiss) and none of the heavy sexuality items (petting above or below the waist, sexual intercourse) were classified as light sexuality only. Adolescents who reported that they had engaged in any of the three heavy sexuality items were classified into the heavy sexuality group. To validate this classification, we conducted a principal components factor analysis of the six sexual activity items. The results of the analysis were consistent with our expectations. A two-factor solution, accounting for $83 \%$ of the total variance, was obtained. Loading on the first factor was the three light sexual behaviors of holding hands, hugging, and kissing with loadings of $.93, .93$, and .88, respectively. On the second factor were the three heavy sexuality items of petting above the waist, petting below the waist, and sexual intercourse, with loadings of .85, .79, and .70, respectively.

The percentages of adolescents classified into each of the three categories are shown in Table 3. Consistent with our expectations, a sizeable number of adolescents were classified as engaging in light sexual activities only. We first used a $t$-test to compare the overall percentages of participants in the no sexuality, light sexuality only, and heavy sexuality categories. Across the three categories, more adolescents reported either no sexual behavior (38\%) or light sexual behavior only (38\%) than adolescents reporting heavy sexuality (24\%), $(t[2,1,779]=-8.03, p<.01)$.

Second, $\chi^{2}$ analyses were conducted to compare the distribution of sexual activity categories by gender and age. These distributions are also shown in Table 3. Among 12-year-olds, more girls were in the light behavior category than boys $\left(\chi^{2}[1,1,856]=6.58, p<.05\right)$. Among 13-yearolds, more girls reported no sexual activity than boys $\left(\chi^{2}[1,1,856]=6.36\right.$, $p<.05$ ). As shown in Table 3, more boys were in the heavy cluster than girls for both age groups. Additionally, more 13-year-olds were in the

TABLE 3

Percentages of 12- and 13-Year-Old Boys and Girls Classified Into Light Sexuality, Heavy Sexuality, and No Sexuality Groups

\begin{tabular}{lccccccc}
\hline & & \multicolumn{2}{c}{ 12-Year-Olds } & & \multicolumn{2}{c}{ 13-Year-Olds } \\
& Total (\%) & Boys (\%) & Girls (\%) & & Boys (\%) & Girls (\%) \\
\hline No sexual activity & 38 & 45 & 44 & & 30 & 36 \\
Light sexuality only & 38 & 34 & 40 & & 38 & 38 \\
Heavy sexuality & 24 & 21 & 16 & & 32 & 26 \\
\hline
\end{tabular}

$N=1,781$ 
heavy sexual behavior category than 12 -year-olds $\left(\chi^{2}[1,1,856]=7.55\right.$, $p<.01)$.

\section{Differential Longitudinal Predictors of Light and Heavy Sexual Behavior}

Structural equation modeling was used to test the hypothesis that light and heavy sexuality have both common and discrete predictors. The hypothesized model shown in Figure 1 was tested using two structural equation models. The first model differentiated participants reporting only light sexual activities to those reporting no sexual activity, using a dummy coded outcome variable. A second model differentiated participants reporting heavy sexual activities from participants reporting light or no sexual activities, using a dummy coded outcome variable. For both models, we expected direct effects on heterosexuality for pubertal maturation and peer self-concept. In the second model differentiating light from heavy sexuality we expected a direct effect of problem behaviors, in addition to pubertal maturation and peer self-concept. In both models, we anticipated parenting processes would be indirectly associated with heterosexuality through perceived peer self-concept and problem behavior.

Before conducting the SEM analyses, we assessed the validity of the observed parenting, peer, and problem behavior variables in measuring the underlying latent constructs. All factor loadings between the measured indicators and their factors were significant and provide evidence of an adequate assessment model. ${ }^{1}$ Next, we conducted correlation analyses of Cycle 1 pubertal maturation, peer-oriented self-concept, parenting processes, and problem behavior with Cycle 2 heterosexual activity classification. These are presented in Table 4.

As shown in Table 4, puberty was moderately correlated with level of heterosexual behavior. Correlations between level of heterosexual behavior, peer self-concept, and problem behavior variables were found to be small. Positive parenting and hostile parenting variables were not correlated to the level of heterosexual behavior classification.

The SEM analyses were conducted using AMOS 4.0 (Arbuckle \& Wothke, 1999). Incomplete data were treated using the maximum-likelihood

\footnotetext{
${ }^{1}$ Factor loadings for latent variables: Family environment $(\mathrm{SES}=.47$; Family Composition $=.47$ ), Positive Parenting $($ Nurturance $=.72$; Monitoring $=.42$; Positive Interaction $=.31$ ), Hostile Parenting (Hostile-Ineffective Parenting $=.70$; Punitive Interactions $=.65$; Inconsistent Parenting $=.40$ ), and Problem Behaviors (Problem-Deviancy $=.41$, Conduct Problems and Aggression $=.83$, Social Aggression $=.55$ )
} 


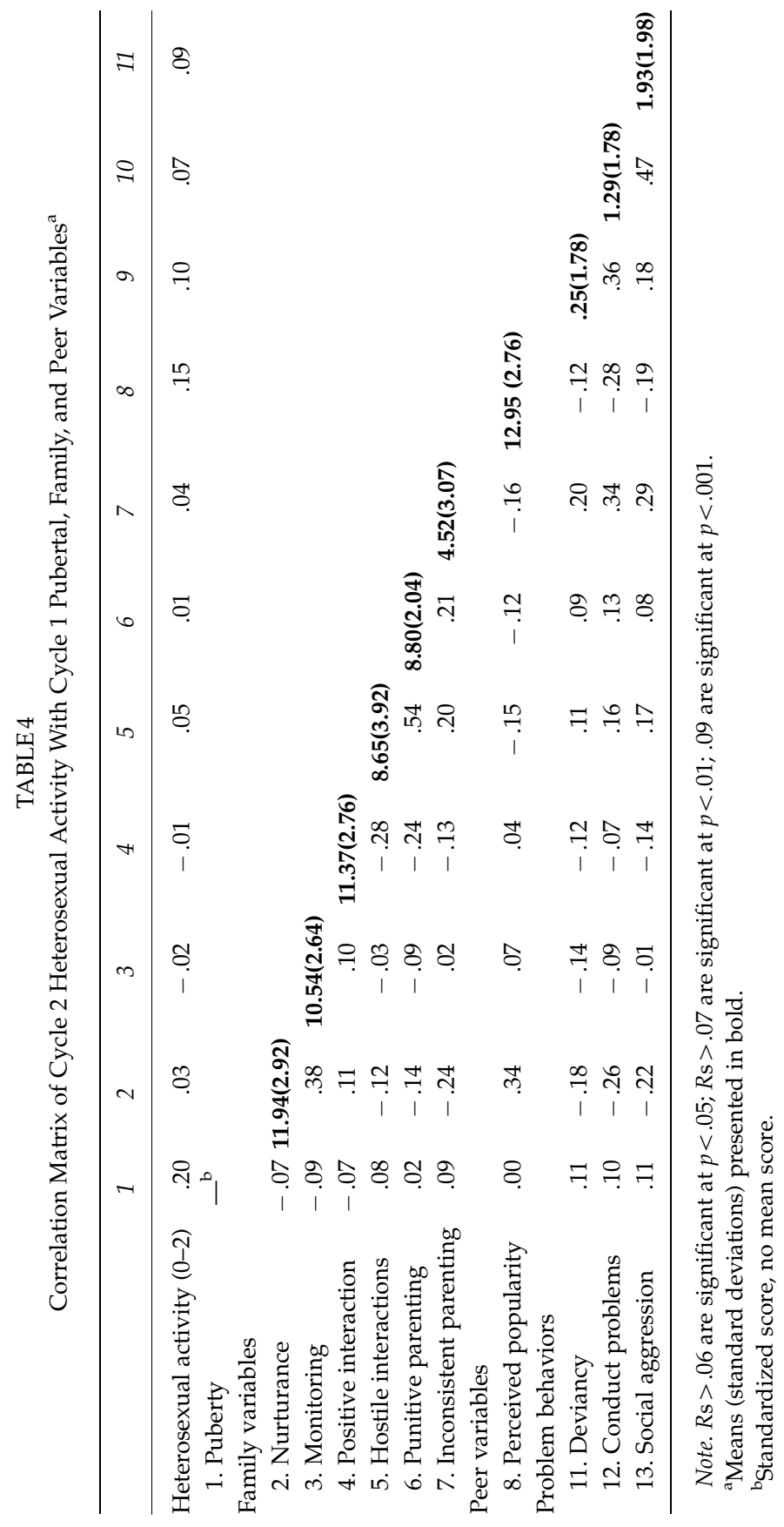


approach available through the AMOS software (Byrne, 2001). AMOS uses full information maximum-likelihood estimation (FIML) with missing data, which results in unbiased parameter estimates and appropriate standard errors when data are missing at random (MAR). The method also assumes continuous, multivariate normal measures, but is robust to violations of this assumption (Hu \& Bentler, 1995). Although not presented in Figure 1, hypothesized relationships were included between the exogenous family environment (SES and family composition), positive parenting, and hostile parenting. Hypothesized covariances were also included between positive and hostile parenting, and peer self-concept and problem behavior constructs. Furthermore, specific relationships were also evaluated between hostile parenting and parental nurturance, as well as punitive parenting and problem behaviors.

Moderation by gender. For each of the models, we followed the multisample approach (Rigdon, Schumacker, \& Wothke, 1998). In this approach two models are computed, one model where the parameters in question are constrained to be equal across the groups, and the other model where the parameters are allowed to differ in the two samples. A nonsignificant $\chi^{2}$ difference suggests that the equality constraints are consistent with the data, and thus an interaction effect does not exist.

For the model predicting light sexuality only, the multisample SEM constraining the structural paths to be equal across gender fit just as well as the model in which these paths were free to vary across gender $\left(\Delta \chi^{2}\right.$ $[11]=7.71$, NS). Similarly, for the model predicting heavy sexuality, the multisample SEM constraining the structural paths to be equal across gender fit just as well as the model in which these paths were free to vary across gender $\left(\Delta \chi^{2}[11]=10.57, \mathrm{NS}\right)$. Remaining analyses subsequently were collapsed across gender.

Light heterosexuality. The first model, testing whether adolescents reporting light sexual activities would be differentiated from adolescents reporting no sexual activity, fit the data well, $\chi^{2}(65, N=1,011)=170.67$, $p<.001, G F I=.98, A G F I=.96, R M S E A=.04$ (90\% CI $=.033-.048)$. The standardized weights for the hypothesized pathways are shown in Figure 2. Both pubertal maturation and peer-oriented self-concept showed significant direct pathways to light sexual activity. Problem behavior was not a significant predictor of light sexual activity. To assess whether parenting processes were indirectly related to heterosexuality, we tested both indirect and direct effects. Positive parenting was not a direct predictor of light sexuality $(\beta=.04, \mathrm{NS})$, but was indirectly associated through peer selfconcept (standardized coefficient for indirect effect $=.03, p<.05$ ). Family 


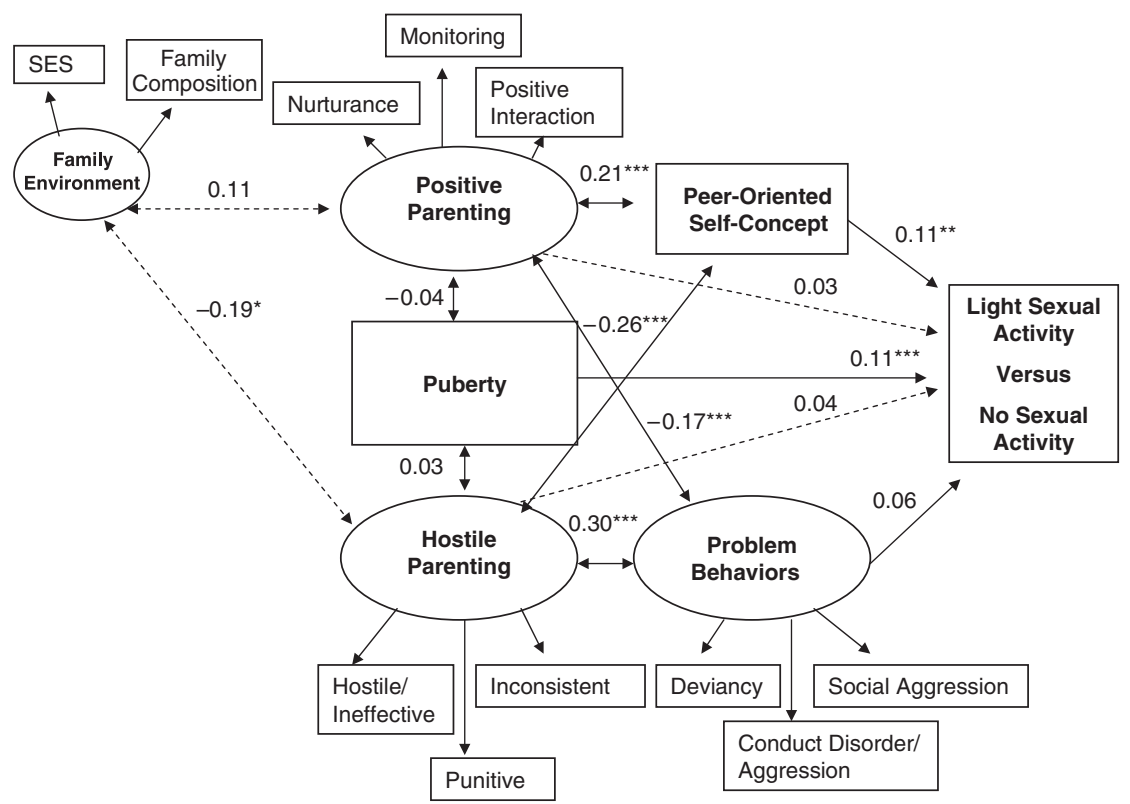

Note. Reported Standardized Regression Weights.

${ }^{\star *} p<.01 ;{ }^{* \star *} p<.001$

FIGURE 2 Structural equation model of differential longitudinal predictors of light heterosexual activity.

hostility was not a direct predictor of light sexuality ( $\beta=.04$, NS), but was indirectly associated through peer self-concept (standardized coefficient for indirect effect $=-.02, p<.05$ ).

Heavy heterosexuality. The second model, testing whether adolescents reporting heavy sexual activities would be differentiated from adolescents reporting light or no sexual activities, indicated a good fit of the model to the data, $\chi^{2}(65, N=1,338)=260.77, p<.001, G F I=.98$, $A G F I=.97, \quad R M S E A=.040 \quad(90 \% \quad C I=.034-.046)$. The standardized weights for the hypothesized pathways are shown in Figure 3. Pubertal maturation and peer self-concept were direct predictors of level of sexual activity. Problem behavior was also a significant direct predictor of level of sexuality. Finally, testing for indirect and direct effects of parenting processes showed that neither positive $(\beta=-.01, \mathrm{NS})$ nor hostile parenting $(\beta=-.01, \mathrm{NS})$ were direct predictors of heavy sexual activity. Hostile parenting was an indirect predictor of heavy sexual activity through problem behavior (standardized coefficient for indirect effect $=.02$, $p<.01$ ) and peer self-concept (standardized coefficient for indirect 


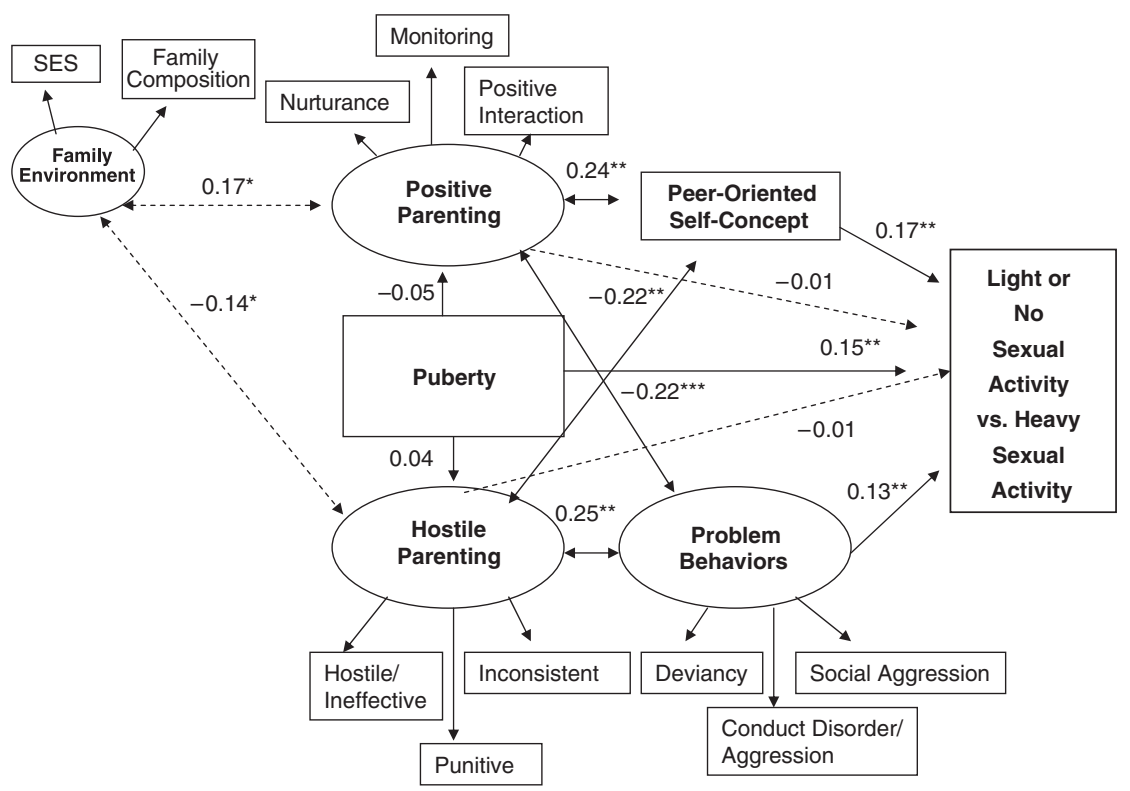

Note. Reported Standardized Regression Weights.

${ }^{\star *} p<.01 ;{ }^{* \star *} p<.001$

FIGURE 3 Structural equation model of differential longitudinal predictors of heavy heterosexual activity.

effect $=-.03, p<.01)$. Positive parenting was also an indirect predictor of heavy sexual activity, through peer self-concept (standardized coefficient for indirect effect $=.03, p<.01$ ), and problem behavior (standardized coefficient for indirect effect $=-.03, p<.01$ ).

\section{DISCUSSION}

The goal of the current study was to extend our understanding of light heterosexual activities in the early adolescent years. Our results document the normative nature of light activities and the less frequent incidence of heavier sexual behaviors, particularly intercourse. In addition, light and heavy sexual activities could be clearly differentiated, such that light behaviors were only associated with normative developmental processes including pubertal maturation and peer self-concept. Finally, our results demonstrated the significance of problem behavior in differentiating pathways of adolescents reporting heavy sexuality. 
Our results provide the first national prevalence rates for a range of early forms of heterosexual behavior among early adolescent Canadians. To date, there are almost no data on heterosexual activity, other than intercourse, among Canadian adolescents, or indeed adolescents from other countries (Maticka-Tyndale, 2001; Maticka-Tyndale et al., 2001). Among our sample of early adolescents, a substantial number of youth reported not engaging in any sexual activities at all. Similarly, the light sexual activities were reported more frequently than the heavier sexual behaviors of petting. Intercourse, consistent with previous findings, was the least frequently reported behavior among this age group. Both the 13-year-olds and the boys, however, reported higher frequencies of the heavy sexual activities, highlighting the continued importance of age and gender in the assessment of adolescent sexuality. Our results suggest only slight differences between the Canadian and American context and reinforce findings of other researchers in suggesting a very low prevalence of young adolescents engaging in intercourse (Halpern et al., 2000; Resnick et al., 1997; Smith \& Udry, 1985). It must be noted, however, that the NLSCY sample size did not allow for separate analyses of non-White youth and it is possible that ethnic differences might lead to differential rates. In addition, our sample is biased toward middle-class adolescents from two-parent homes, thus limiting the generalizability of our rates of heterosexual activity to this population.

A significant accomplishment of the current study was to demonstrate two distinct clusters of heterosexual behaviors. Of those adolescents reporting any heterosexual activity, the majority indicated that they engaged in only light sexual activities. These results suggest that light activities, in the absence of heavy sexuality, represent a phase of development in which youth may limit their sexual conduct. It is possible that some youth may feel that they are not ready, or mature enough, to engage in more serious and intimate forms of sexuality. Young adolescents may also not have the opportunities for heavier sexual activities to occur since their dating activities are largely group-based (e.g., Connolly \& Johnson, 1996; Connolly et al., 2004; Feiring, 1999). A smaller, yet substantial number of adolescents also reported heavy sexuality, such as petting, along with light activities. We know that there is a progression from lighter forms of sexual behavior to heavier activities and clearly there are some adolescents in our sample who have made this transition. Our data do, however, highlight the significant number of youth who restrict themselves to light behaviors at this age, in all likelihood making the transition to heavier behavior at some point later in adolescence. As investigators, it is important to recognize the significance of both of these finding so that future studies encompass a range of sexual behaviors beyond intercourse to 
better understand the earlier forms of heterosexuality during this time in development.

A major goal of this study was to extend current models of early adolescent heterosexuality to distinguish no sexuality from light sexuality, as well as to differentiate between light and heavy behaviors. To better understand the factors associated with early adolescent heterosexuality, the current study examined a normative developmental pathway including positive parenting and personal peer self-concept as well as replicating the problem behavior model (Capaldi et al., 1996). In the normative model, light heterosexuality was associated with normative biological, family, and peer processes. In the problem behavior model, in addition to these predictors, heavy heterosexuality was also associated with an atypical pathway including problem behaviors. These findings emphasize the shared and unique factors related to light and heavy heterosexuality in early adolescence. It is important to recognize that the relationships found between early heterosexual behavior, puberty, peer, and family factors span only 1 year. Further longitudinal research is needed to confirm and further develop the associations demonstrated in the current study.

In the first model, adolescents engaging only in light sexual activities were successfully differentiated from adolescents reporting no sexual involvement utilizing normative developmental predictors. Light sexual behavior on its own was not associated with problem behaviors. These results confirm that some early sexual activities among adolescents can be considered appropriate as they are associated with developmental processes normally occurring at this time. The transition of puberty has long been associated with the onset of sexual behavior; however, the research predominantly has focused on links with heavy sexual behavior, namely intercourse (e.g., French \& Dishion, 2003; Udry, 1990). The current study extends these findings by highlighting the relationship between pubertal development and lighter forms of heterosexuality. Our results suggest that pubertal development is linked to more normative sexual behaviors without co-occurring risky levels of sexuality. Light sexuality was also predicted by heightened peer self-concept. This demonstrates that as adolescents' attention increasingly shifts toward perceived popularity with their peers, so too does their interest and opportunities for early sexual involvement. Engaging with friends and peers socially, not surprisingly, offers an arena for early forms of heterosexual behavior to occur. This is an important finding, as peers are often considered only in terms of their negative influences on adolescent behavior (e.g., Capaldi et al., 1996; Tubman et al., 1996). Future research should continue to investigate peer self-concept and peer relations in early adolescence, to identify characteristics of the peer group that may regulate or limit sexual activity 
to lighter, less risky behavior. Finally, positive and hostile parenting indirectly differentiated adolescents engaging in light sexual activities only from adolescents reporting no activity. These results show that positive and hostile parenting are inversely associated with an adolescent's peer self-concept, which in turn is linked to light sexuality. In contrast to hostile parenting, positive parenting, which includes monitoring and positive family time, may enable the adolescent to feel more secure in transferring his or her attention to their peer group without severing family ties.

In the problem behavior model, adolescents engaging in heavy sexual activities were successfully differentiated from adolescents engaging in light or no sexual behavior, by their reports of increased problem behavior, in addition to increased pubertal maturity and heightened peer selfconcept. These results are consistent with problem behavior theory, demonstrating that heavy sexual behavior in early adolescence emerges from a trajectory including other risky behaviors such as aggression, conduct problems, and drug and alcohol use (Capaldi et al., 1996, 2002; Jessor \& Jessor, 1977; Jessor et al., 1991, 1995). Adolescents engaging in risky sexual behaviors are also on significantly earlier physical developmental timetables. Adolescents engaging in heavy sexuality were the most pubertally advanced at age 10 and 11, suggesting precocious pubertal development. Additionally, these adolescents' peer self-concepts were significantly higher than adolescents reporting light or no sexual activity. This suggests that heavy sexuality is strongly associated with a significant shift toward peer group involvement, perhaps indicating strong alignments with peers, and less orientation toward other social arenas, namely their families and community ties.

Parenting processes were found to be indirectly associated with heavy sexual behavior. Hostile parenting was indirectly associated to heavy sexuality through its positive relationship with problem behaviors and negative relationship with peer-oriented self-concept. Positive parenting was also indirectly associated with heavy sexuality through its negative relationship with problem behavior and its positive relationship with peer-oriented self-concept. For adolescents engaging in heavy sexuality, parenting practices contributed to higher problem behaviors, as well as heightened peer self-concept. It is interesting to note that positive parenting processes were indirectly linked to heavy sexuality. It is possible that these linkages reflect the inverse correlation between hostile and positive parenting or the mediating role of peer self-concept. We can also speculate that this link reflects a permissive style of parenting in which nurturance is associated with high tolerance for an early transition to adult sexuality. Further research is clearly needed to clarify this indirect link. Taken as a 
whole, these results confirm the indirect role that family processes play in early adolescents' trajectories of risky sexual behavior.

An important contribution of this research is that it highlights the importance of examining early adolescent heterosexuality as a normally developing behavior. In the North American environment, messages about adolescent heterosexuality can be very skewed toward negative and explicit images. Not surprisingly, there is a lack of solid information on what is appropriate and healthy in early adolescence and how these behaviors might differ from those that are viewed as risky. It is consequently very important that information regarding patterns of early sexual activity among young Canadian adolescents be communicated to parents, educators, and adolescents. As the media increasingly normalizes sexual behavior in adolescence, youth can lose track of the fact that such heavy sexual activities are, in fact, uncommon. Knowing what constitutes normal activity can counteract the tendency to endorse more extreme behaviors as acceptable. In particular, parents, educators, and adolescents can benefit from knowing that light sexual behaviors can be considered normative at this time, whereas heavy sexual behavior, especially intercourse, is not.

Some limitations of the present study should be noted. The NLSCY sample provides an important window on sexuality among White, middle-class youth in Canada. However, it is important to note that the findings should not be generalized to youth from diverse socioeconomic or ethnic backgrounds. In addition, the current study focuses on heterosexual activities and does not include the possibility of homosexual or autosexual activity. A sizeable minority of Canadian youth identify as either sexual minority or questioning their sexual orientation during adolescence (Williams, Connolly, Pepler, \& Craig, 2003, 2005). Consequently, the predictors that we established for heterosexual activity may not pertain for nonheterosexual youth. We also acknowledge that some of the measures assessing parenting processes had only moderate internal consistencies, although this was at least partially remedied by combining them into latent factors. Moreover, peer self-concept could have been strengthened with the addition of contextual variables such as the age and gender composition of the peer group (Connolly et al., 2004; Magnusson, Stattin, \& Allen, 1985). Without this information we cannot separate perceptions of popularity within the peer group from its characteristics. Finally, caution is warranted in making causal interpretations from the current findings. The 1-year longitudinal design does not allow us to determine whether sexual activity preceded, followed, or co-occurred with related parenting, pubertal development, misbehavior, and peer self-concept measures. A broader longitudinal design that includes younger 
children and families is needed to sort out the nature of such causal relationships.

To conclude, the current study represents an initial examination of early heterosexual behavior among young Canadian adolescents. The results articulate a picture of both light and heavy heterosexual activities among these youth and highlight their distinct developmental pathways. Further research should now be directed to a consideration of longer-term outcomes of both normal and atypical patterns of adolescent sexual activity.

\section{REFERENCES}

Achenbach, T. M., \& Edelbrock, C. S. (1991). Manual for the youth self-report and profile. Burlington, VT: Department of Psychiatry, University of Vermont.

Alan Guttmacher Institute. (2001). Can more progress be made? Teenage sexual and reproductive behavior in developed countries. New York: The Alan Guttmacher Institute.

Arbuckle, J. L., \& Wothke, W. (1999). Amos 4.0 user's guide. Chicago, IL: SPSS Inc.

Brooks-Gunn, J., \& Furstenberg, F. F. Jr. (1989). Adolescent sexual behavior. American Psychologist, 44, 249-257.

Brown, B. B. (1999). You're going with who?!: Peer group influences on adolescent romantic relationships. In W. Furman, B. B. Brown, \& C. Feiring (Eds.), The development of romantic relationships in adolescence (pp. 291-329). London, UK: Cambridge University Press.

Brown, B. B., Mounts, N., Lamborn, S. D., \& Steinberg, L. (1993). Parenting practices and peer group affiliation in adolescence. Child Development, 64, 467-482.

Byrne, B. (2001). Structural equation modeling with AMOS: Basic concepts, applications and programming. Mahwah, NJ: Erlbaum.

Capaldi, D., Stoolmiller, M., Clark, S., \& Owen, L. (2002). Heterosexual risk behaviors in atrisk young men from early adolescence to young adulthood: Prevalence, prediction, and association with STD contraction. Developmental Psychology, 38, 394-406.

Capaldi, D. M., Crosby, L., \& Stoolmiller, M. (1996). Predicting the timing of first sexual intercourse for at-risk adolescent males. Child Development, 67, 344-359.

Capaldi, D. M., \& Patterson, G. R. (1994). Interrelated influences of contextual factors on antisocial behavior in childhood and adolescence for males. In D. Fowles, P. Sutker, \& S. H. Goodman (Eds.), Experimental personality and psychopathy research (pp. 165-198). New York: Springer.

Carskadon, M. A., \& Acebo, C. (1993). A self-administered rating scale for pubertal development. Journal of Adolescent Health, 14, 190-195.

Cavanagh, S. (2004). The sexual debut of girls in early adolescence: The intersection of race, pubertal timing, and friendship group characteristics. Journal of Research on Adolescence, 14, 285-312.

Coley, R., \& Chase-Lansdale, P. (1998). Adolescent pregnancy and parenthood: Recent evidence and future directions. American Psychologist, 53, 152-166.

Connolly, J. A., Craig, W., Goldberg, A., \& Pepler, D. (2004). Mixed-gender groups, dating, and romantic relationships in early adolescence. Journal of Research on Adolescence, 14, 185-207.

Connolly, J. A., \& Johnson, A. (1996). Adolescents' romantic relationships and the structure and quality of their close interpersonal ties. Personal Relationships, 3, 185-195. 
Coplan, R. J., Findlay, L. C., \& Nelson, L. J. (2004). Characteristics of preschoolers with lower perceived competence. Journal of Abnormal Child Psychology, 32, 399-408.

Crockett, L., Bingham, C., Chopak, J., \& Vicary, J. (1996). Timing of first sexual intercourse: The role of social control, social learning, and problem behavior. Journal of Youth and Adolescence, 25, 89-111.

Donenberg, G., Bryant, F., Emerson, E., Wilson, H., \& Pasch, K. (2003). Tracing the roots of early sexual debut among adolescents in psychiatric care. Journal of the American Academy of Child and Adolescent-Psychiatry, 42, 594-608.

Donovan, J., \& Jessor, R. (1985). The structure of problem behavior in adolescence and young adulthood. Journal of Consulting and Clinical Psychology, 53, 890-904.

Dufour, J., Gambino, J., Kennedy, B., Lindeyer, J., \& Singh, M. P. (1998). Methodology of the Canadian Labour Force Survey. Ottawa, ON: Statistics Canada.

Elliott, D. S., \& Morse, B. J. (1989). Delinquency and drug use as risk factors in teenage sexual activity. Youth and Society, 21, 32-60.

Ellis, B. J., \& Garber, J. (2000). Psychosocial antecedents of variation in girls' pubertal timing: Maternal depression, stepfather presence, and marital and family stress. Child Development, 71, 485-501.

Feiring, C. (1999). Other-sex friendship networks and the development of romantic relationships in adolescence. Journal of Youth and Adolescence, 28, 495-512.

Feldman, S., Rosenthal, D., Brown, N., \& Canning, R. (1995). Predicting sexual experience in adolescent boys from peer rejection and acceptance during childhood. Journal of Research on Adolescence, 5, 387-411.

French, D., \& Dishion, T. (2003). Predictors of early initiation of sexual intercourse among high-risk adolescents. Journal of Early Adolescence, 23, 295-315.

Grunbaum, J., Kann, L., Kinchen, S., Ross, J., Hawkins, J., Lowry, R., et al. (2004). Youth Risk Behavior Surveillance-United States, 2003. Morbidity and Mortality Weekly Report, 53, $1-100$.

Grunbaum, J., Kann, L., Kinchen, S., Williams, B., Ross, J., Lowry, R., et al. (2001). Youth Risk Behavior Surveillance-United States, 2001. Morbidity and Mortality Weekly Report, 51, $1-64$.

Halpern, C., Joyner, K., Udry, J., \& Suchindran, C. (2000). Smart teens don't have sex (or kiss much either). Journal of Adolescent Health, 26, 213-225.

Hartup, W. W. (1979). The social worlds of childhood. The American Psychologist, 34, 944-950.

Holmbeck, G. N., \& Hill, J. P. (1991). Conflictual engagement, positive affect, and menarche in families with seventh-grade girls. Child Development, 62, 1030-1048.

Hu, L., \& Bentler, P. M. (1995). Evaluating model fit. In R. H. Hoyle (Ed.), Structural equation modeling: Concepts, issues, and applications (pp. 76-99). Newbury Park, CA: Sage.

Jacobson, K., \& Crockett, L. (2000). Parental monitoring and adolescent adjustment: An ecological perspective. Journal of Research on Adolescence, 10, 65-97.

Jessor, R., Donovan, J., \& Costa, F. (1991). Beyond adolescence: Problem behavior and young adult development. New York: Cambridge.

Jessor, R., \& Jessor, J. (1977). Problem behavior and psychosocial development: A longitudinal study of youth. New York: Academic Press.

Jessor, R., Van Den Bos, J., Vanderryn, J., Costa, R., \& Turbin, M. (1995). Protective factors in adolescent problem behavior: Moderator effects and developmental change. Developmental Psychology, 31, 923-933.

Kann, L., Kinchen, S., Williams, B., Ross, J., Lowry, R., Hill, C., et al. (1998). Youth Risk Behavior Surveillance-United States, 1997. Journal of School Health, 68, 355-369.

Kotchick, B., Shaffer, A., \& Forehand, R. (2001). Adolescent sexual risk behavior: A multisystem perspective. Clinical Psychology Review, 21, 493-519. 
Ladd, G. W., \& Pettit, G. S. (2002). Parents' and children's peer relations. In M. H. Bornstein (Ed.), Handbook of parenting (2nd ed., pp. 269-310). Mahwah, NJ: Erlbaum.

Lagerspetz, K., Björkqvist, K., \& Peltonen, T. (1988). Is indirect aggression typical of females? Gender differences in aggressiveness in 11 to 12 year old children. Aggressive Behavior, 14, 403-414.

Lammers, C., Ireland, M., Resnick, M., \& Blum, R. (2000). Influences on adolescents' decision to postpone onset of sexual intercourse: A survival analysis of virginity among youth aged 13 to 18 years. Journal of Adolescent Health, 26, 42-48.

Larson, R., \& Richards, M. (1991). Daily companionship in late childhood and early adolescence: Changing developmental contexts. Child Development, 62, 284-300.

Larzelere, R. E., \& Patterson, G. R. (1990). Parental management: Mediator of effect of socioeconomic status on early delinquency. Criminology, 28, 301-323.

Laub, J., \& Sampson, R. (1988). Unraveling families and delinquency. Criminology, 26, 355-380.

Lempers, J. D., Clark-Lempers, D. C., \& Simons, R. L. (1989). Economic hardship, parenting, and distress in adolescence. Child Development, 60, 25-39.

Lynch, C. (2001). Risk and protective factors associated with adolescent sexual activity. Adolescent and Family Health, 2, 99-107.

Magnusson, C. (2001). Adolescent girls' sexual attitudes and opposite-sex relations in 1970 and in 1996. Journal of Adolescent Health, 28, 242-252.

Magnusson, D., Stattin, H., \& Allen, V. L. (1985). Biological maturation and social development: A longitudinal study of some adjustment processes from mid-adolescence to adulthood. Journal of Youth and Adolescence, 14, 267-283.

Marsh, H. W., \& Gouvernet, P. J. (1989). Multidimensional self-concepts and perceptions of control: Construct validation of responses by children. Journal of Educational Psychology, 81, $57-69$.

Maticka-Tyndale, E. (2001). Sexual health and Canadian youth: How do we measure up? Canadian Journal of Human Sexuality, 10, 1-18.

Maticka-Tyndale, E., McKay, A., \& Barrett, M. (2001). Country report for Canada. Occasional Report No. 4. New York, NY: Alan Guttmacher Institute.

Michaud, S. (1999). The National Longitudinal Survey overview and changes after three cycles. Paper presented at Workshop on Longitudinal Research in Social Science. October 25-27.

Montemayer, R. (1983). Parents and adolescents in conflict: All families some of the time and some families most of the time. Journal of Early Adolescence, 3, 83-103.

Mott, F., \& Quinlan, S. (1993). The ten-and-over years: Self-reports from the children of the NLSY. Columbus, OH: Center for Human Resource Research, The Ohio State University.

Newcomer, S., \& Udry, J. (1985). Oral sex in an adolescent population. Archives of Sexual Behavior, 14, 41-46.

Newcomer, S., Udry, J. R., \& Cameron, F. (1983). Adolescent sexual behavior and popularity. Adolescence, 18, 515-522.

Patterson, G. R., Reid, J. B., \& Dishion, T. J. (1992). Antisocial boys. Eugene, OR: Castalia.

Petersen, A., Crockett, L., Richards, M., \& Boxer, A. (1988). A self-report measure of pubertal status: Reliability, validity, and initial norms. Journal of Youth and Adolescence, 17, 117-133.

Pettit, G., Bates, J., Dodge, K., \& Meece, D. (1999). The impact of after-school peer contact on early adolescent externalizing problems is moderated by parental monitoring, perceived neighborhood safety, and prior adjustment. Child Development, 70, 768-778.

Phinney, V. G., Jensen, L. C., Olsen, J. A., \& Cundick, B. (1990). The relationship between early development and psychosexual behaviors in adolescent females. Adolescence, 25, 321-332.

Pineo, P., Porter, J., \& McRoberts, H. (1977). The 1971 census and socio-economic classification of occupations. Canadian Review of Sociology and Anthropology, 14, 91-102. 
Resnick, M., Bearman, P., Blum, R., Bauman, R., Harris, K. M., Jones, J., et al. (1997). Protecting adolescents from harm: Findings from the national longitudinal study on adolescent health. Journal of the American Medical Association, 278, 823-832.

Rigdon, E. E., Schumacker, R. E., \& Wothke, W. (1998). A comparative review of interaction and nonlinear modeling. In R. E. Schumacker \& G. A. Marcoulides (Eds.), Interaction and non-linear effects in structural equation (pp. 1-16). Mahwah, NJ: Lawrence Erlbaum Associates.

Rockett, J., Lynch, C., \& Buck, G. (2004). Biomarkers for assessing reproductive development and health: Part 1-pubertal development. Environmental Health Perspectives, 112, 105-112.

Rosenthal, D., \& Smith, A. (1997). Adolescent sexual timetable. Journal of Youth and Adolescence, 26, 619-636.

Smith, E. A., \& Udry, J. R. (1985). Coital and non-coital sexual behaviors of white and black adolescents. American Journal of Public Health, 75, 1200-1203.

Statistics Canada. (1996). 1996 Census.

Steinberg, L. (1990). Autonomy, conflict, and harmony in the family relationship. In S. S. Feldman \& G. R. Elliott (Eds.), At the threshold: The developing adolescent (pp. 255-276). Cambridge, MA: Harvard University Press.

Steinberg, L. (2001). We know some things: Adolescent-parent relationships in retrospect and prospect. Journal of Research on Adolescence, 11, 1-20.

Steinberg, L., \& Morris, A. S. (2001). Adolescent development. Annual Review of Psychology, 52, 83-110.

Strayhorn, J., \& Weidman, C. (1988). A parent practices scale and its relation to parent and child mental health. Journal of the American Academy of Child and Adolescent Psychiatry, 27, 613-618.

Tubman, J., Windle, M., \& Windle, R. (1996). Cumulative sexual intercourse patterns among middle adolescents: Problem behavior precursors and concurrent health risk behaviors. Journal of Adolescent Health, 18, 182-191.

Udry, J. R. (1979). Age at menarche, at first intercourse, and at first pregnancy. Journal of Biological Sciences, 11, 411-433.

Udry, J. R. (1990). Hormonal and social determinants of adolescent sexual initiation. In J. Bancroft \& M. Reinisch (Eds.), Adolescence and puberty (pp. 70-87). Oxford: Oxford University Press.

Udry, J. R., \& Billy, J. O. G. (1987). Initiation of coitus in early adolescence. American Sociological Review, 52, 841-855.

Williams, T., Connolly, J., Pepler, D., \& Craig, W. (2003). Questioning and sexual minority adolescents: High school experiences of bullying, sexual harassment and physical abuse. Canadian Journal of Community Mental Health, 22, 47-58.

Williams, T., Connolly, J., Pepler, D., \& Craig, W. (2005). Peer victimization, social support and psychosocial adjustment of sexual minority adolescents. Journal of Youth and Adolescence, 34, 471-482.

Zweig, J., Phillips, S., \& Duberstein-Lindberg, L. (2002). Predicting adolescent profiles of risk: Looking beyond demographics. Journal of Adolescent Health, 31, 343-353. 
Copyright (C) 2008, Crown Copyright 